\title{
Screening of Wheat Genotypes Against Leaf Rust Under Artificial and Natural Environmental Condition
}

\author{
Saqib Yamin1, Javed Asgar Tariq, Raza' Muhammad Memon ${ }^{1,}$ Sadam Hussain Bhutto ${ }^{1,2}$, and \\ Muhammad Usman Asif \\ ${ }^{1}$ Nuclear Institute of Agriculture (NIA) TandoJam Sindh, Pakistan \\ ${ }^{2}$ Rice Research Institute, Sichuan Agricultural University, Chengdu, China \\ Corresponding author: jatariq_1411@yahoo.com \\ Article Received 05-07-2020, Revised 28-10-2020, Accepted 12-12-2020
}

\section{ABSTRACT}

Rust diseases are considered to be responsible for significant qualitative and quantitative damages on wheat. However, the severity of rust diseases can be managed through development of resistant lines. The present study was aimed to scrutinize existing wheat germplasm against leaf rust and stripe rust of wheat. For this purpose 30 wheat genotypes were assessed for disease resistance under artificial inoculation conditions and 16 genotypes were evaluated under natural conditions at Nuclear Institute for Agriculture (NIA), Tandojam, Pakistan. The disease severity ratings were taken according to Cobs'scale. The studies revealed that wheat genotypes were markedly differed in their resistance to leaf and stripe rust. Among the tested wheat lines / varieties, 6 were rated as resistant, 6 moderately resistant, 13 showed MRMS type response, 2 showed moderately susceptible reaction, 3 lines/varieties displayed susceptible response against leaf rust under artificial conditions. Moreover, under natural conditions 1 was rated as resistant, 2 showed MRMS type response against leaf rust and all were found resistant or immune against stripe rusts under both the conditions. Hence, it was suggested that resistant genotypes evaluated from these studies can be deployed in the future breeding strategies to evolve the resistant varieties against leaf \& stripe rusts of wheat.

Key words: wheat, screening, resistant, susceptibility, rusts

\section{INTRODUCTION}

Wheat (Triticum aestivum) crop is attacked by many diseases, that causes major losses to wheat yield, are leaf yellow rust \& stripe rusts. These rust diseases pose a constant threat to sustainable wheat production and food security in Asia (Hussain et al., 1980 and Singh et al. 2004). These are prevalent throughout the world and their new races are evolving unremittingly, day by day and infecting resistant varieties (Waqar et al., 2018). If susceptible wheat cultivars are grown, then approximately 40 to 60 million hectares could experience periodic epidemics of leaf and stripe rust, respectively. Leaf rust appears during March-April in the form of orange color pustules, scattered on leaf and leaf sheath. Early infection may even kill the plant while the late infections reduce the overall yield. "The leaf rust disease can create chronic problem due to its time of appearance and prolonged season for its development". (Khan et al., 1997). Yellow rust appears on leaves as small yellowish pustules arranged in lines parallel to veins (Ahmad et al., 2010). The damage caused depends upon the severity and time of infection resulting into yield reduction. It may appear in January and continue to develop in March depending upon the prevalence of low temperature. Stripe rust can cause yield losses from 10 to $100 \%$ (Yuan et al., 2018). Several epidemics of leaf and stripe rusts on wheat crop have been reported in the past and these diseases continue to be major threat to future wheat production. (Ahmad et al., 2010) \& (Raza et al., 2018). The worst yellow rust 
Yamin et al.,

epidemic in the recent years has wiped out almost all the commercial wheat varieties of the country. So, avoiding major rust epidemics in the region is a complex challenge. Moreover, new races of leaf rust, stripe rust and stem rust have been introduced into wheat production areas in different continent this is another issue to be addressed. The best management for the control of rust diseases is to screen out the available germplasm against yellow and brown rusts. To determine their level of resistance and to estimate yield losses, detailed research is required, particularly in relation to different rust intensities. The amount of rust diseases and their correlation with yield can be helpful to develop a model which may be used in future to predict not only the rust diseases but also the yield losses on wheat by these diseases. Rust severity of the tested varieties could be used to assess the resistance behavior of the plant (Ali et al., 2007). At present, country is facing critical shortage of appropriate wheat varieties having both feature of high yield and rust resistance with wider adoptability. Therefore, present studies were designed to sort out rust resistant genotypes to ovoid yield losses

\section{MATERIALS AND METHODS}

Screening of wheat germplasm under artificial conditions: 30 genotypes were grown at NIA, Tandojam, Sindh, to observe their rust response and performance in agro climatic conditions of this area. Wheat lines were sown
J. appl. Res in Plant Sci. Vol. 2(1), 115-120, 2021 www.joarps.org.

on $3^{\text {rd }}$ week of December. Hand drill was used for sowing purpose. Each line was planted in one $\mathrm{cm}$ row. Randomized complete block design was used in the experiment. Morocco was used as a susceptible check and was sown at border of plot and was also repeated after each ten rows. All agricultural inputs were given to the crop at recommended rates. The material was artificially inoculated at booting stage of crop. The crop was sprayed daily with urediospores suspension of rust fungi up to appearance of symptoms. Field was visited regularly to observe disease appearance.

Disease scoring: Fourteen days, after inoculation disease appeared. Small brown pustules develop on the leaf blades in a random scatter distribution. The pustules were circular, slightly elliptical, and smaller than those of stem rust. Usually contain masses of orange to orange-brown urediospores. Infection sites primarily were found on the upper surfaces of leaves and leaf sheath and occasionally on the neck and awns. Data in the field was recorded as severity and response. For this purpose, Modified Cobbs' scale was used which represents six degrees of rust lines viz., 5, 10, 20, 30,65 , and $100 \%$. The $100 \%$ severity accounts for $37 \%$ of the actual leaf area covered. Below $5 \%$ severity trace to $2 \%$ intervals are used. The response of a variety refers to the infection type and is classified according to the following letters

Modified Cobbs' Scale used for Scoring

\begin{tabular}{|c|l|}
\hline Letter & Infection type \\
\hline $\mathrm{O}$ & No visible infection \\
\hline $\mathrm{R}$ & Resistant: necrotic areas with or without small pustules. \\
\hline MR & Moderately resistant: medium sized pustules; no necrosis, but some chlorosis possible. \\
\hline MS & Moderately resistant: medium sized pustules; no necrosis, but some chlorosis possible. \\
\hline S & Susceptible: large pustules; no necrosis or chlorosis. \\
\hline X & Intermediate. pustules of variable size; some necrosis and or chlorosis \\
\hline
\end{tabular}


Severity and response readings are recorded together with severity at first. Some examples are given below.

$\mathrm{TR}=$ trace severity of a resistant type infection $10 \mathrm{MR}=10 \%$ severity of a moderately resistant type $50 \mathrm{~S}=50 \%$ range of reaction on each plant

\section{Screening of germplasm under natural} conditions: Breeding material consisting of 16 wheat lines/varieties were planted at Nuclear Institute of Agriculture (NIA) experimental farm. The experiment was conducted on $2^{\text {nd }}$ week of November. For sowing purpose hand drill was used. Length of each entry was kept as 1 meter. RCBD Design was applied in the experiment. All agricultural inputs were given to the crop at recommended doses. Field was kept free and no rust inoculation was done. Experiment was visited regularly to observe disease appearance. Disease severity ratings of rusts were taken from appearance of initial symptoms up to crop maturity using the Cobbs scale.

\section{RESULTS AND DISCUSSIONS}

Genetic resistance is the most economic and effective means of reducing yield losses caused by leaf rust disease (Liu and Kolmer, 1997). In the current work, varying degree of resistance and susceptibility was observed against wheat leaf rust. Among tested 30 lines / varieties under artificial conditions, 6 lines showed resistant response, 6 moderately resistant, 13 genotypes showed MRMS type reaction, 2 displayed MS-S type reaction, and 3 fell susceptible. Moreover, in case of stripe rust, it appeared in natural conditions in same trial. 2 genotypes were screened as resistant, and remaining genotypes showed immune response. This variability in virulence of advance wheat lines might be due to their genotypic behavior (Aktar-Uz-Zamana et al., 2017; Hussain et al., 2011; Rattu et al., 2009). The resistant wheat lines may have some resistant set of stable genes. These new sources of leaf rust resistance can be incorporated into wheat to escape heavy yield losses. These results are supported by the findings of other researchers (Hussain et al., 2011; Kolmer et al., 2007; Stepien et al., 2003). During 2010-2012 growing seasons, Draz et al. (2015) evaluated 42 Egyptian wheat varieties for leaf rust resistance and only 9 varieties exhibited seedling and adult plant resistance. They also elaborated that inverse relation exists between the disease level and grain yield. Muhammad et al. (2015) screened three hundred and twenty-five wheat genotypes on the basis of leaf rust severity scale and revealed that 225 wheat genotypes showed no reaction against leaf rust, 12 genotypes showed resistant response, 20 moderately resistant, 40 moderately susceptible, 15 moderately resistant to moderately susceptible and 13 genotypes showed susceptible response against leaf rust. They also described that epidemiological factors remained highly significant for leaf rust development and had great influence on the development of leaf rust of wheat. Breeding disease resistance genotypes is a continuous process and plant breeders need to add new effective genes to their breeding materials. Resistance expression depends on the host-parasite interaction, environmental conditions, plant growth stage and the interaction between resistance genes in wheat genome (Kolmer, 1996). New sources of resistance could be incorporated into wheat to diverse the existing gene pool for leaf rust resistance (Singh et al., 1998). Among 16 lines / varieties tested under natural conditions, 1 genotype showed Rtype reaction, two showed MRMS type reaction against leaf rust while remaining all were immune against stripe rust. Indigenous germplasm screened against stripe rust in field condition indicated that most of the lines were immune after the resistance status which is suggested to use in the wheat breeding program because resistant varieties are the best option for successful wheat production (Admassu et al., 2012). From these studies it can be concluded that source of resistance are present in wheat tested germplasm. If this material is tested for other agronomic traits in different agro-climatic zone of Pakistan and satisfactory results are achieved, then these cultivars can be deployed in breeding program to release resistant varieties or these wheat germplasm as cultivars, these advanced lines which are genetically improved 
Yamin et al.,

elite cultivars, can better adapt in our local conditions as successful varieties. Thus, this approach can greatly help to increase and stabilize agriculture productivity as well as avert epidemics if seed of resistant varieties are made
J. appl. Res in Plant Sci. Vol. 2(1), 115-120, 2021 www.joarps.org.

available to the farmers on a timely basis. Walker (1965) considered screening as important tool for evaluation of resistance. Many successes can be quoted of such productive programs

Table-1. Response of Wheat genotypes against Leaf and Stripe Rust under artificial conditions

\begin{tabular}{|c|c|c|}
\hline Sr. No & Leaf rust Response & Stripe rust Response \\
\hline 1 & 5MRMS & $\mathrm{O}$ \\
\hline 2 & $5 \mathrm{~S}$ & $\mathrm{O}$ \\
\hline 3 & 5MRMS & $\mathrm{O}$ \\
\hline 4 & 10MRMS & $\mathrm{O}$ \\
\hline 5 & 5RMR & $\mathrm{R}$ \\
\hline 6 & $5 \mathrm{MS}$ & $\mathrm{O}$ \\
\hline 7 & $10 \mathrm{MR}$ & $\mathrm{O}$ \\
\hline 8 & 20MRMS & $\mathrm{O}$ \\
\hline 9 & $5 \mathrm{R}$ & $\mathrm{R}$ \\
\hline 10 & $5 \mathrm{MR}$ & $\mathrm{O}$ \\
\hline 11 & $\mathrm{R}$ & $\mathrm{O}$ \\
\hline 12 & $5 \mathrm{~S}$ & $\mathrm{O}$ \\
\hline 13 & TMR & $\mathrm{O}$ \\
\hline 14 & 20MRMS & $\mathrm{R}$ \\
\hline 15 & $\mathrm{R}$ & $\mathrm{O}$ \\
\hline 16 & 10MRMS & $\mathrm{O}$ \\
\hline 17 & $\mathrm{R}$ & $\mathrm{O}$ \\
\hline 18 & 20MRMS & $\mathrm{O}$ \\
\hline 19 & $40 \mathrm{~S}$ & $\mathrm{O}$ \\
\hline 20 & 30MRMS & $\mathrm{R}$ \\
\hline 21 & 20MRMS & $\mathrm{O}$ \\
\hline 22 & $5 \mathrm{MS}-\mathrm{S}$ & $\mathrm{O}$ \\
\hline 23 & 5MRMS & $\mathrm{O}$ \\
\hline 24 & $\mathrm{R}$ & $\mathrm{O}$ \\
\hline 25 & 20MRMS & $\mathrm{O}$ \\
\hline 26 & 10MRMS & $\mathrm{O}$ \\
\hline 27 & $10 \mathrm{R}$ & $\mathrm{O}$ \\
\hline 28 & $5 \mathrm{MR}$ & $\mathrm{O}$ \\
\hline 29 & TMR & $\mathrm{O}$ \\
\hline 30 & 5MRMS & $\mathrm{O}$ \\
\hline
\end{tabular}

Table-2. Response of Wheat genotypes against Leaf and yellow Rust under artificial conditions

\begin{tabular}{|l|l|l|}
\hline Sr. No & Leaf rust & Yellow rust \\
\hline 1 & R & O \\
\hline 2 & O & O \\
\hline 3 & O & O \\
\hline 4 & O & O \\
\hline 5 & O & O \\
\hline 6 & O & O \\
\hline 7 & 5 MRMS & O \\
\hline 8 & O & O \\
\hline 9 & O & O \\
\hline 10 & O & O \\
\hline
\end{tabular}




\begin{tabular}{|l|l|l|}
\hline 11 & 5MRMS & O \\
\hline 12 & O & O \\
\hline 13 & O & O \\
\hline 14 & O & O \\
\hline 15 & O & O \\
\hline 16 & O & O \\
\hline
\end{tabular}

\section{References}

Afzal, S. N., Haque, I., Ahmedani, M.S., Munir, M., Firdous, S. S., Rauf, A., Ahmed, I., Rattus, A. R and Fayyaz, M. (2009). Resistance Potential of Wheat Germplasm (TriticumAestivum L.) Against Stripe Rust Disease under Rained Climate of Pakistan. Pak. J. Bot, 41(3), 1463-1475.

Afzal, S. N., Haque, M. I., Ahmedani, M.S., Bashir, S., and Rattur, A. (2007). Assessment of Yield Losses caused by (Puccinia Striform Riggering) Stripe rust in the most common wheat varieties. Pak. J. Bot, 36(6), 2127-2134.

Ahmad, s., Zfzal, M., Noorka, I. R., Iqbal, Z., Akhtar, N., Iftkhar, Y and Kamran, M. (2010). Prediction of yield losses in wheat (triticum aestivum 1.) caused by yellow rust in relation to epidemiological factors in faisalabad. Pak. J. Bot, 42(1), 401-407.

Ali, S., Jawad, S., Shah, A. and Ibrahim, A. (2007). Assessment of Wheat Breeding Lines for Slow Yellow Rusting (Puccinia Striiforms West. Tritici). Pak. J. Biol. Sci, 10(19), 3440-3444.

Anwar, M. J., Javed, M. A., Jamil, M. W., Habib, I., Nazir, S., Rehman, S., Iqbal M. Z., Kamran, M., Haq, M. E., (2019). Response of wheat genotypes for resistance against leaf rust (puccinia triticina eriks.) Under field conditions. Plant Protection, 03 (01), 35-39.
Bux, H., Ashraf, M., Hussain, F., Rattu, A.-UrR., \& Fayyaz, M. (2012). Characterization of wheat germplasm for stripe rust (Puccini striiformisf. sp. tritici) resistance. A. J. C. S, 6(1), 116-120.

Dangl, J. L., Horvath,D. M., Staskawicz, B. J. (2013). Pivoting the plant immune system from dissection to deployment. Science, 341(6147), 46-51.

Draz, I. S., Elseoud M. S. A., Kamara, A. E. M.,Alaa-Eldein, O. A. E., El-Bebany A. F.(2015). Screening of wheat genotypes for leaf rust resistance along with grain yield. Annals of Agricultural Science, 60(1), 29-39.

Fayyaz, M., Rattu, A. R., Ahmad, I., Akhtar, M. A., Hakro, A. A. and Kazi, A. M. (2008). Current status of the occurrence and distribution of (puccinia triticina) wheat leaf rust virulence in pakistan. Pak. J. Bot, 40(2), 887-895.

Hussan, M., Hussan, S. F., and Kirmni, M. A. S. (1980). Virulence in Puccinia reccindita Rob.ex Desm. F. sp. Tritci in Pakistan during 1978 and 1979. Proceedings of the fifth European and Mediterranean Cereal Rust Conference, Bari, Italy.pp.179-184.

Khan, M.A., Trevathan, L.E., and Robbin, J.T. (1997). Quantitative relationship between leaf rust and wheat yield in Mississippi. Plant Disease, 81,769-772. 
Yamin et al.,

Kolmer, J. A., Long, D. L., Hughes, M. E. (2005). Physiologic Specialization of Puccinia triticina on wheat in the United States in 2003. Plant Disease. 89 (11), 1201-1206.

Marasas, C. N., Smale, M., Singh, R.P. (2004).

The economic impact in developing countries of leaf rust resistance breeding in CIMMYT-related spring bread wheat. International Maize and Wheat Improvement Center, Mexico, DF.

Qamar, M., Ahemd, S. D., Shah, A. H., Wellings, C. R., and Batoob, F. (2008). Postulation of Stripe Rust Resistant Genes in Some Australian Bread Wheat Cultivars and Their Response to Temperature. Pak. J. Bot, 40(6), 25732585 .

Raza, W., Ghazanfar, M. U., Rehman, A. and Fayyaz, M. (2018). screening of wheat germplasm against stripe rust disease under field conditions in Pakistan. Plant Protection, 02 (03), 87-92.
J. appl. Res in Plant Sci. Vol. 2(1), 115-120, 2021 www.joarps.org.

Singh R.P., William, H. M., Huerta-Espino, J., Rosewarne, G. (2004). Wheat rust in Asia: Meeting the challenges with old and new technologies. In: New directions for a diverse planet. Proceedings of the 4th International Crop Science Congress, Brisbane, Australia

Walker, J. C. (1965). Use of environmental factors in screening of resistance. Ann. Rev. Phytopathol, 3.197-208.

Waqar, A., Khattak, S. H., Begum, S., Rehman, T.., Rabia, Shehzad, A., Ajmal, W., Zia, S. S., Siddiqi, I., Ali, G. M. (2018). Stripe rust: A review of the disease, $\mathrm{Yr}$ genes and its molecular markers. Sarhad J. Agri, 34(1), 188-201.

Yuan, F.P., Zeng, Q.D., JH, W.u., Wang, Q. L., Yang, Z.J., Liang, B. P. (2018). QTL mapping and validation of adult plant resistance to stripe rust in Chinese wheat landrace humai. Front Plant Sci, 104(5), 1-13. 